\title{
Level of Practical Skills in Personnel Dosimetry Monitoring and the Laboratory Experience with Different Types of TLD Readers
}

\author{
H. K. Agyeman ${ }^{1}$, B. J. B. Nyarko1,2, S. Osae ${ }^{1,2}$, F. Adeku², E. O. Darko1,2, J. K. Amoako', ${ }^{1,2}$ \\ J. Owusu-Banahene1,2, S. Inkoom ${ }^{1,2}$, B. K. Agyeman'1, P. Manteaw ${ }^{1}$, E. Amoatey ${ }^{1}$, \\ G. 0. Aseidu1, P. Appiah1, B. D. Bekoe1, D. F. Charles' \\ ${ }^{1}$ Radiation Protection Institute, Ghana Atomic Energy Commission, Accra, Ghana \\ ${ }^{2}$ Graduate School of Nuclear and Allied Sciences, University of Ghana, Atomic Campus, Accra, Ghana \\ Email: ^jewel5w@yahoo.com
}

How to cite this paper: Agyeman, H.K., Nyarko, J.B.B., Osae, S., Adeku, F., Darko, E.O., Amoako, J.K., Owusu-Banahene, J., Inkoom, S., Agyeman, B.K., Manteaw, P., Amoatey, E., Aseidu, G.O., Appiah, P., Bekoe, B.D. and Charles, D.F. (2019) Level of Practical Skills in Personnel Dosimetry Monitoring and the Laboratory Experience with Different Types of TLD Readers. International Journal of Medical Physics, Clinical Engineering and Radiation Oncology, 8, 141-150.

https://doi.org/10.4236/ijmpcero.2019.83013

Received: May 29, 2019

Accepted: August 18, 2019

Published: August 21, 2019

Copyright $\odot 2019$ by author(s) and Scientific Research Publishing Inc. This work is licensed under the Creative Commons Attribution International License (CC BY 4.0).

http://creativecommons.org/licenses/by/4.0/

\section{(c) (i) Open Access}

\begin{abstract}
This study was carried out to analyze individual annual dose records of diagnostic radiology staff at forty-eight (48) different medical facilities in urban and rural Region of Ghana for the period of 2011-2015. The monitored dose data were extracted from the Radiation Protection Institute of the Ghana Atomic Energy Commission's database called the Dose Management System (DMS). The doses of these OEWs analyzed, are divided into four subgroups namely; general radiographers, radiologists, computed tomography (CT) technologists, fluoroscopy technologists. The dose distribution, collective dose and mean annual dose were determined. A total of 1574 OEWs were monitored comprising of $56 \%$ radiographers, $15 \%$ radiologist, $21 \%$ computed tomography (CT) technologists and $8 \%$ fluoroscopy technologists. The average annual effective dose ranged from 0.36 to $1.70 \mathrm{mSv}$ with radiographers receiving the largest. Fluoroscopy technologist recorded the least annual total collective effective dose value of 0.1 person-Sv. The study contributes to the existing works to promote a more comprehensive personal monitoring service for OEWs. Continued analysis of occupational doses should be an integral component of institutional radiation safety programs in Ghana.
\end{abstract}

\section{Keywords}

Doses, Radiologist, Occupationally Expose Workers, Dose Management System and Database

\section{Introduction}

Occupational exposure to radiation occurs in Ghana as a result of practices such 
as work with radiation sources and $\mathrm{x}$-ray units in medicine, scientific research and teaching, nuclear devices used in agriculture, and industry and occupations that involve the handling of materials containing concentrations of naturally occurring radionuclides [1]. The use of ionizing radiations and radioisotopes in medicine has increased dramatically since last 2 - 3 decades due to its broad spectrum of application and technological improvements in diagnosis and treatment modalities. The International Commission on Radiation Protection (ICRP) and International Atomic Energy Agency (IAEA) had been working for a long time for the promotion of the radiation protection system in medicine. The occupational radiation exposure of the workers carrying out ionizing radiationinclined practices in medicine had become more important and regulatory bodies all over the world are more concerned about its monitoring and record keeping. Therefore the radiation exposures of the occupational personnel involved in radiation oriented practices are monitored and assessed throughout the world.

The Personal Dosimetry Laboratory of RPI provides Thermoluminescent dosimeter (TLD) badges to Occupationally Exposed Workers in Ghana on either monthly or quarterly frequency and assess the occupational exposure due to external radiation sources using the Dose Management System (DMS) as a comprehensive tool and a software known as Win REMS as a tool to improve monitoring in Ghana [2]. Since the RPI is the only body that provides dosimetry service for facilities that employ the use of ionizing radiation in Ghana, its database represents data on all monitored workers in Ghana within the period 2011-2015.

Analysis of occupational doses is an important component of institutional radiation protection programs. Appropriation of radiation protection resources should take into account dose variation among various occupational groups. Highly exposed groups should be appropriated more resources in terms of training, provision of protective devices and implementation of dose reduction schemes [3].

This study was designed to analyze individual annual dose records of diagnostic radiology staff at forty-eight (48) medical facilities in Ghana for the period 2011-2015. Diagnostic radiology staff was categorized into four (4) occupational subgroups, namely, general radiographers, radiologists, CT technologists and fluoroscopy technologists. The dose distribution, annual collective dose and mean annual dose for each subgroup are presented and analyzed. Statistical analysis is expected to generate information useful to the management of the hospital's radiation safety program. Conclusions drawn from this study may also be of general interest to other medical institutions and radiation safety practitioners and can be used as indicators of good institutional radiation safety practices [4] [5].

\section{Materials and Method}

The TLD badge consists of the standard Harshaw (Thermo Electron Corpora- 
tion, 6801 Cochran Road, Solon, Ohio 44139, USA) two (2) or four (4) element TLD-100 (LiF:Mg, Ti) card and holder type 8814 with appropriate filters for measurement of the personal dose equivalents at depths of $10 \mathrm{~mm}$ [Hp (10)] and $0.07 \mathrm{~mm}$ [Hp (0.07)], that is, Deep dose and Skin dose as shown in Figures 1-7 respectively.

The pictures show Different types of Thermoluminescent Dosimeter (TLD) Badge.

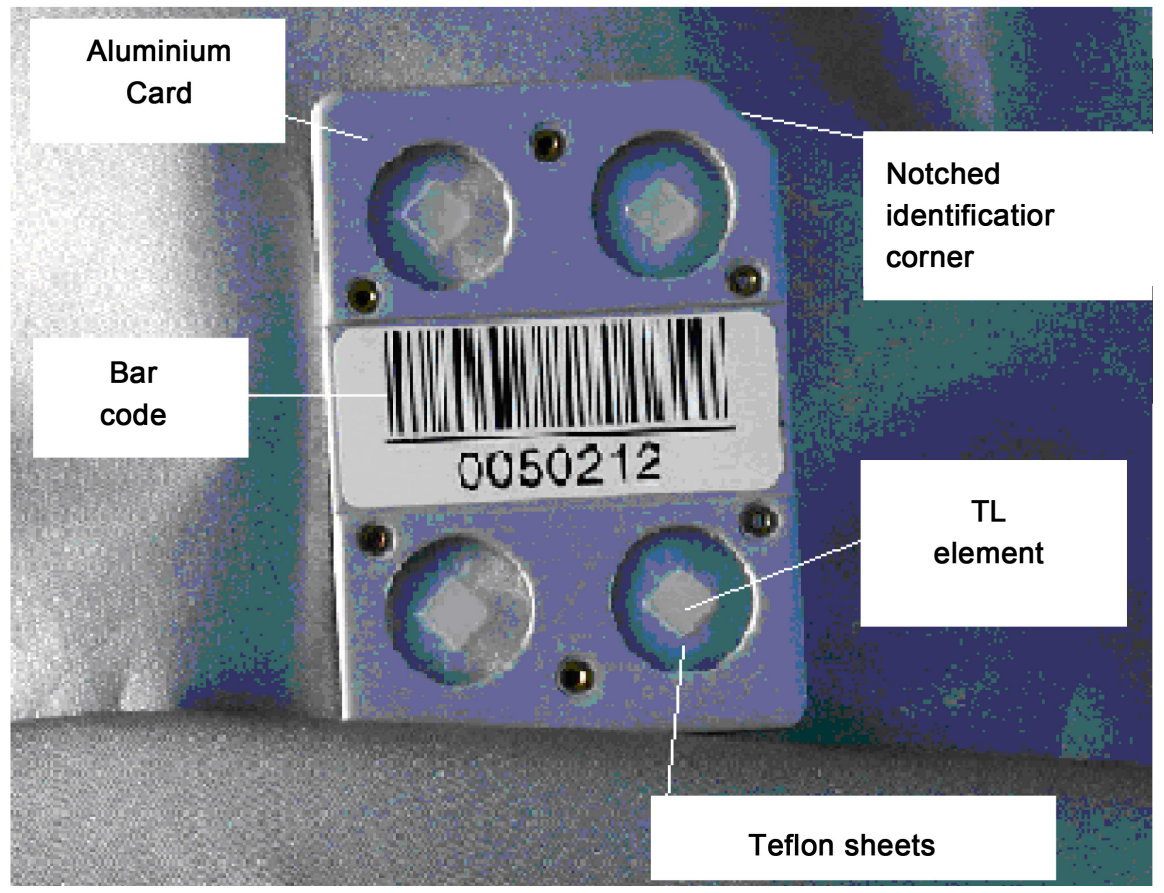

Figure 1. Shows a detailed description of a thermo fisher scientific TLD Card. TPYE: 0110, C.O \#: 198067, COLOR: blue.

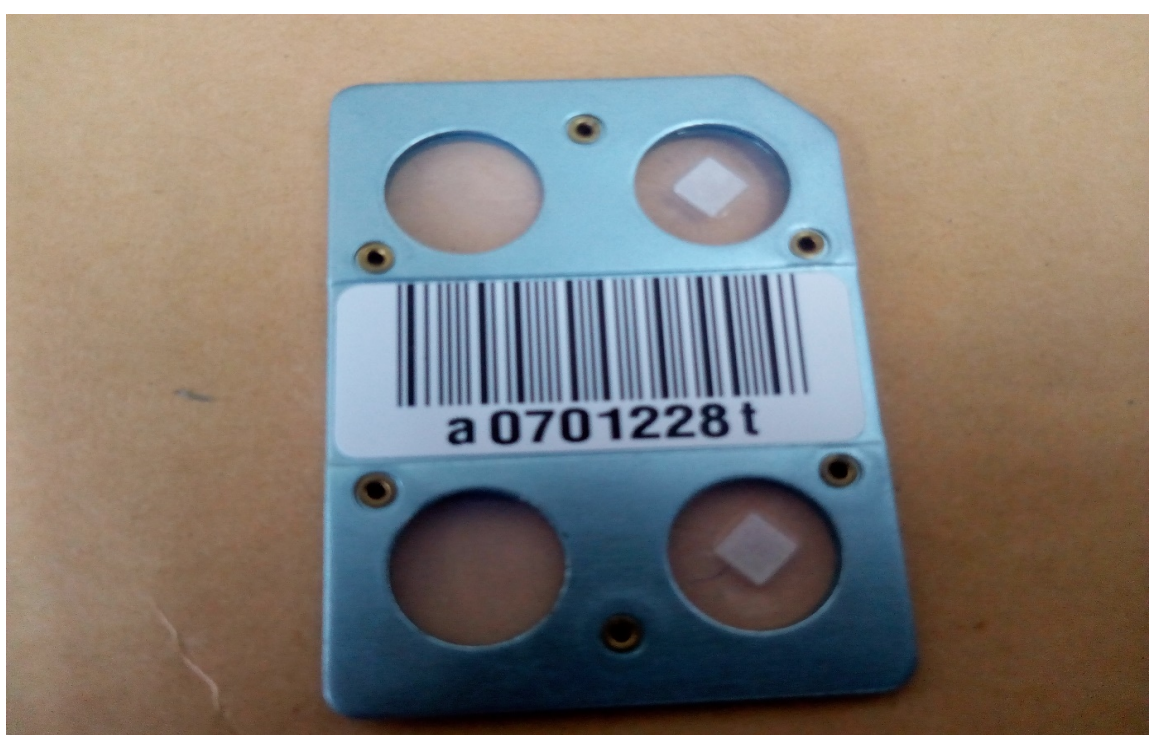

Figure 2. Shows a picture of thermo fisher scientific TLD card. TPYE: 0110. C.O \#: 198067. COLOR: blue. 


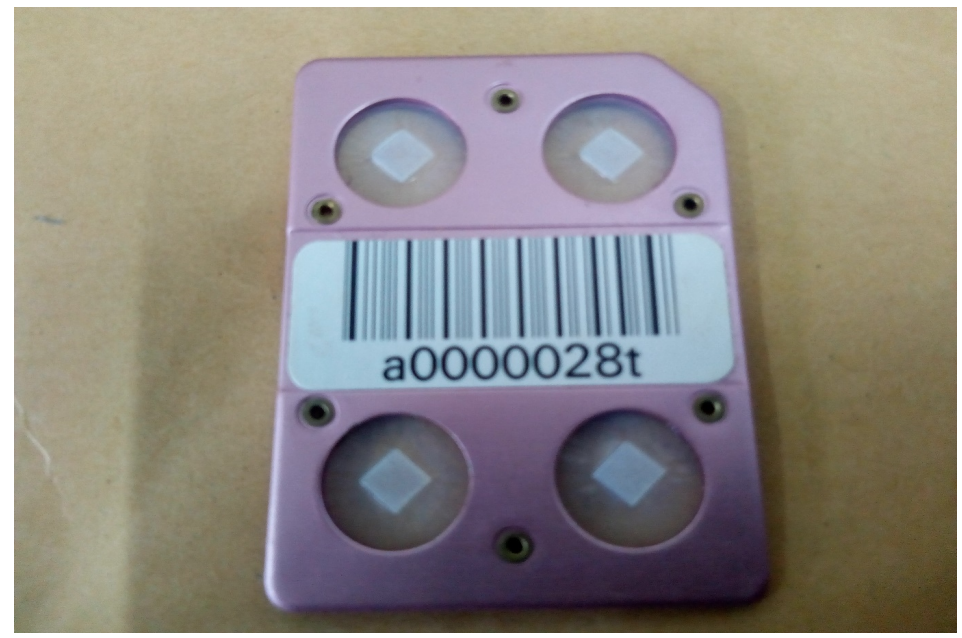

Figure 3. Shows a picture of thermo fisher scientific TLD card. TPYE: 0110. C.O \#: 198067. COLOR: peach.

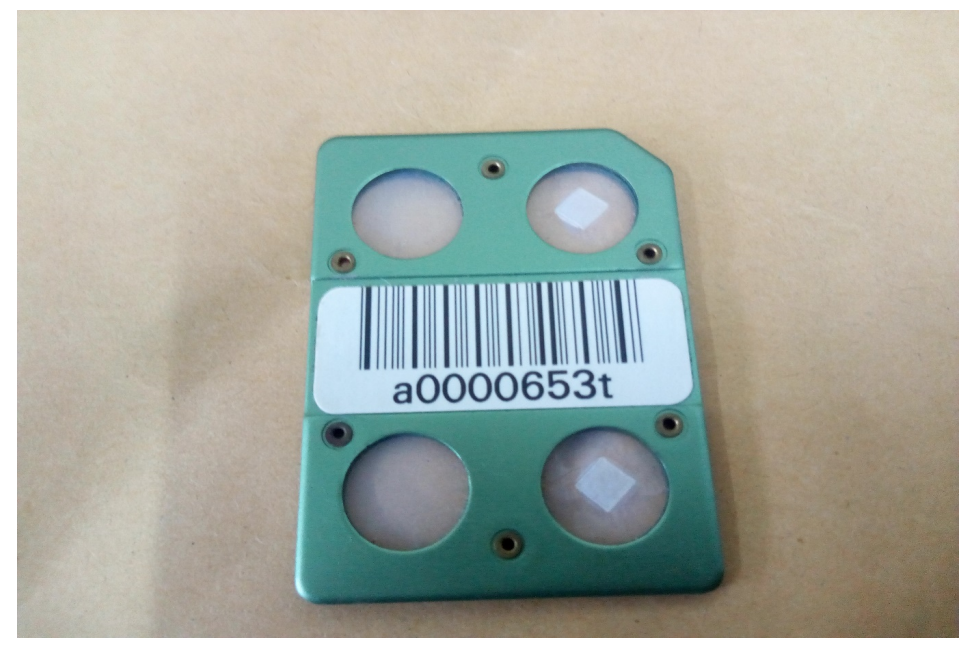

Figure 4. Shows a picture of thermo fisher scientific TLD card. TPYE: 0110. C.O \#: 198067. COLOR: green.

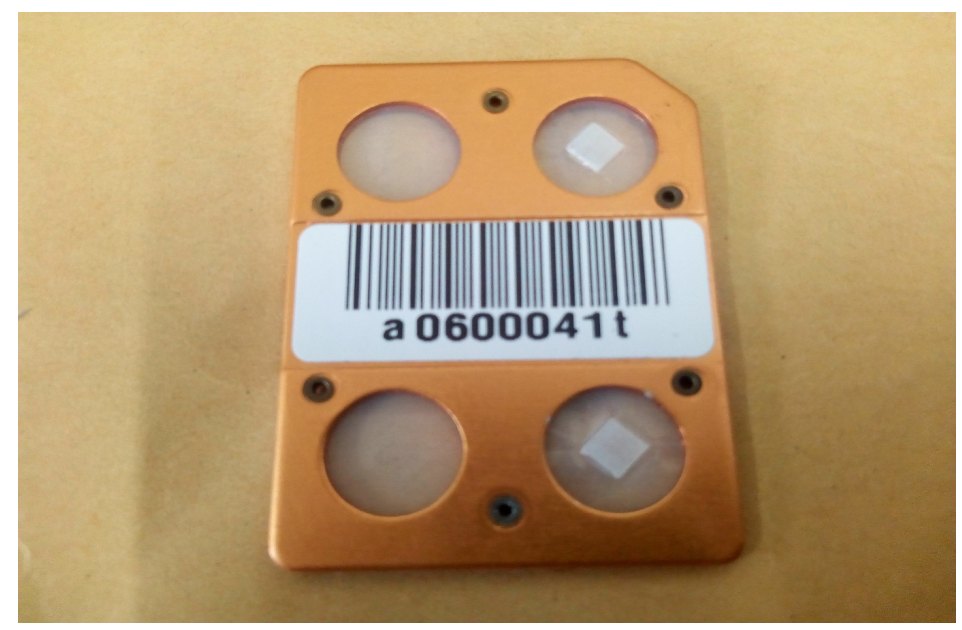

Figure 5. Shows a picture of thermo fisher scientific TLD card. TPYE: 0110. C.O \#: 198067. COLOR: copper. 


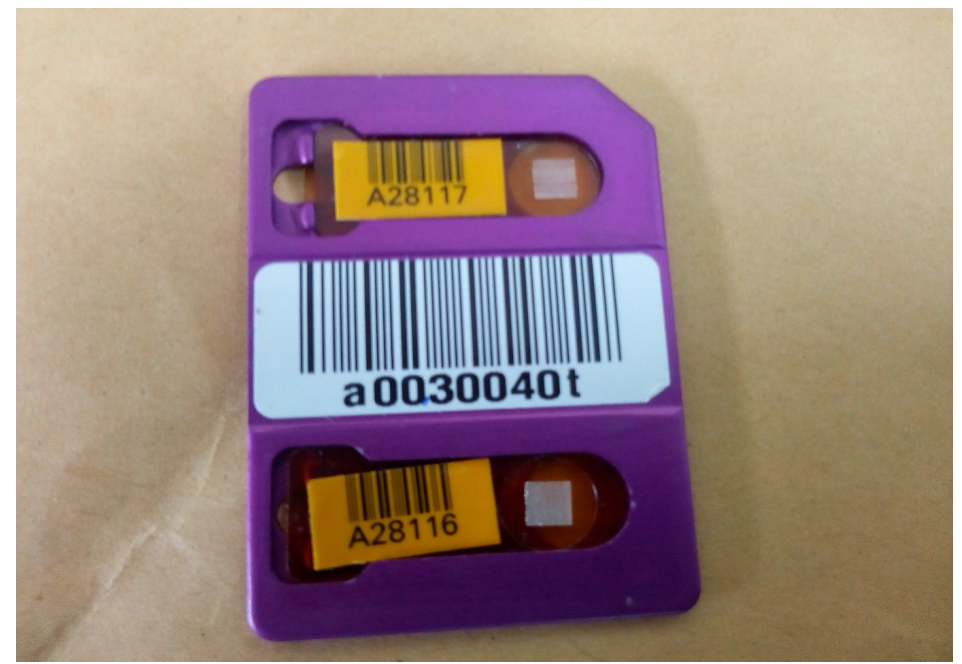

Figure 6. Shows a picture of thermo fisher scientific TLD card (single chip). TPYE: 0110. C.O \#: 198067. COLOR: violet.

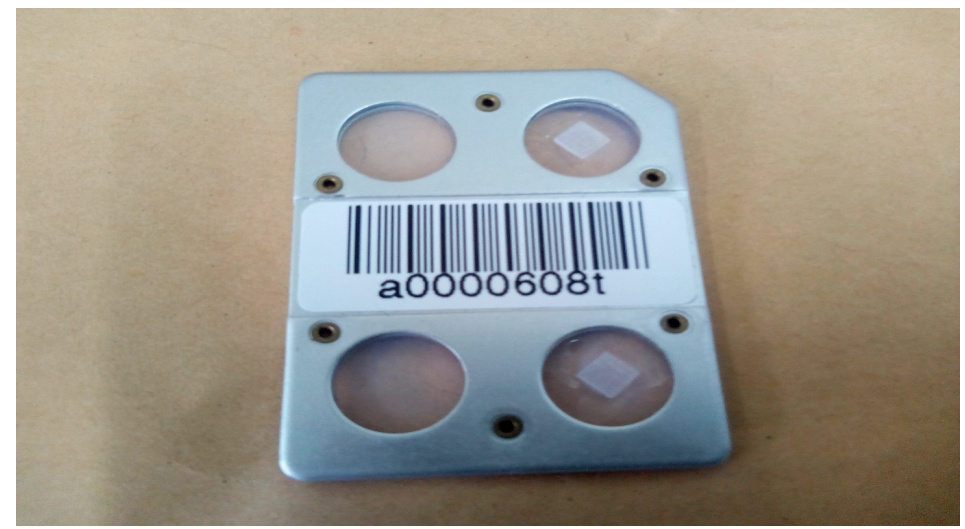

Figure 7. Shows a picture of thermo fisher scientific TLD cards. TPYE: 0110. C.O \#: 198067. COLOR: grey.

\section{Harshaw 6600 plus TLD Reader}

The Harshaw 6600 TLD reader system as shown in Figure 8 with serial number 9805167, used to read the TLD cards has the ability to monitor whole body (for beta, photon and neutron radiation), extremity and environmental exposure, with a single dosimeter. It can take up to 200 dosimeters per

Reading cycle and also saves significant time by virtue of its automatic calibration capabilities. The Harshaw TLD reader is connected to an external personal computer (PC), and is operated through installed menu-driven Win REMS software.

Dosimetry report generation and the subsequent electronic storage of dose records are accomplished using the DMS. TLD card labels, which include a bar-coded unique number, the wearer's name and institution, are generated by the PDL. Personnel dose records from 1997 to the present are stored electronically in the DMS. The RPI dosimetry service currently provides routine monitoring to about 2000 radiation workers throughout the country [6] [7]. 


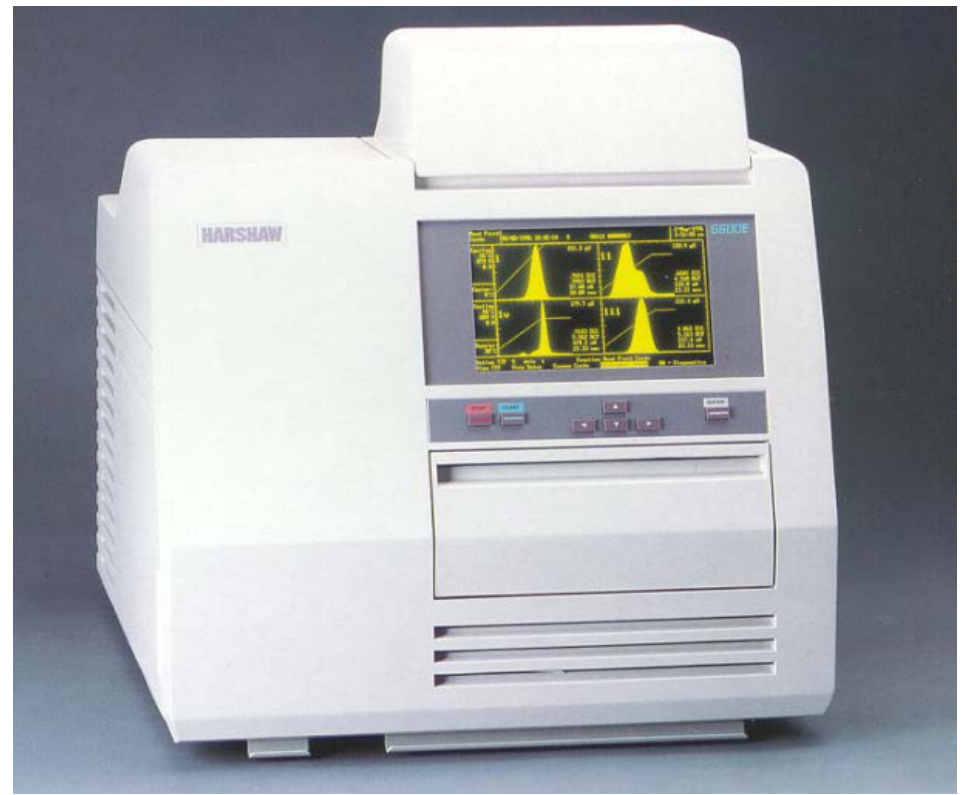

Figure 8. Shows a picture of Harshaw 6600 PLUS TLD reader.

The DMS calculates the "year-to-date" dose, which is the sum of the doses from January up to the current month of a specific year. Thus, the "year-to-date" dose for December represents the worker's annual dose [8].

In this study, annual dose records of diagnostic radiology staff in the medical facilities for the period 2011-2015 were retrieved from the DMS and exported to Excel 2010 for analysis [9] [10]. The number of monitored exposed workers for each of the four previously mentioned categories is presented; as well as the dose distribution, annual collective dose and the mean annual dose.

The mean annual dose,

$$
E_{m}=\frac{\sum W_{T} H_{T}}{N}
$$

where $H_{T}$ is the equivalent dose in tissue $T$ and $W_{T}$ is the tissue weighting factor for tissue $T$.

$N=$ number of measurement in a year.

The annual collective dose, $S$, is given by

$$
S=\sum_{j=1}^{r} N_{j} E_{j i}
$$

where $E_{j i}$ is the annual dose calculated for the $f^{\text {th }}$ reading of the $i^{\text {th }}$ worker and $N$ is the number of workers in a facility and $r$ is the number of measurement in a year.

\section{Results and Discussion}

The graph, Figure 9 show occupational radiation exposures of workers involved in ionizing radiation oriented practices in medical facilities. The minimum detectable limit is $0.1 \mathrm{mSv}$ and the annual dose limit is $20 \mathrm{mSv}$ averaged over five 


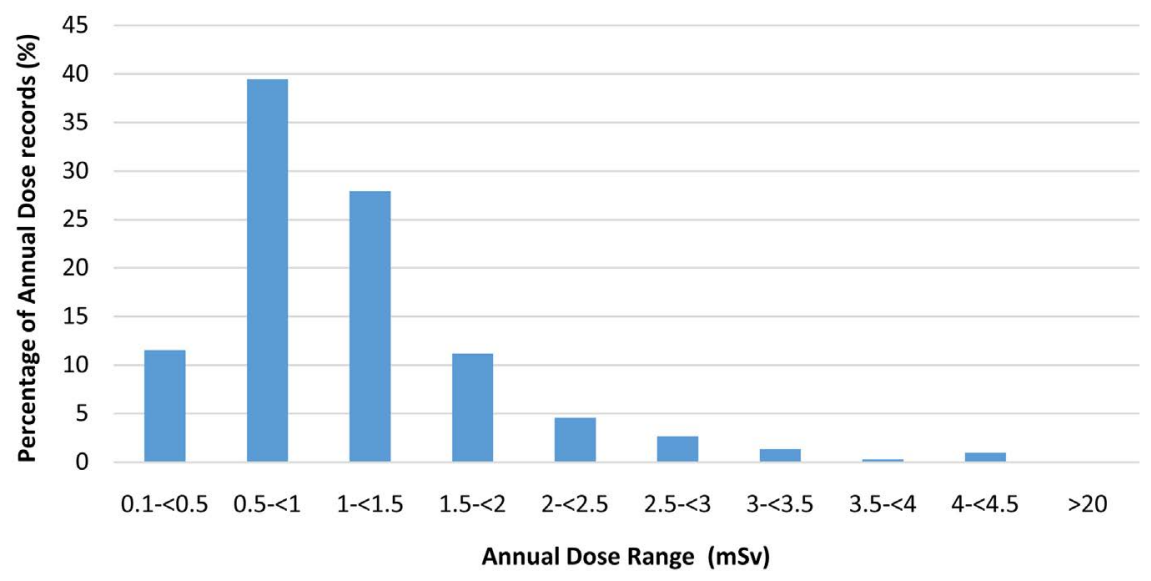

Figure 9. Shows dose distribution of annual dose records from 2011-2015.

years.

Figure 3 indicates the distribution of annual personal dose records from 2011 to 2015; about $51 \%$ were below $1 \mathrm{mSv}$ and $49 \%$ between $1 \mathrm{mSv}$ and $5 \mathrm{mSv}$.

Table 1 demonstrates the annual average effective dose of all the occupationally exposed workers falls in the range of $0.36-1.70 \mathrm{mSv}$. The highest annual average effective dose $1.70 \mathrm{mSv}$ was found in Radiographers category in the year 2015. This could be due to the increased number and operations of $\mathrm{x}$-ray radiography facilities.

Table 2 demonstrates the annual collective dose and their percentage contribution, averaged over the five (5) year period for the various category of workers in Ghana. General radiography recorded the highest collective dose followed by CT technology, radiology, and fluoroscopy technology which are 21.87 person Sv (89.14\%), 1.58 person Sv (5.98\%), 0.85 person Sv (3.73\%) and 0.27 person Sv (1.16\%) respectively. The range of annual total collective effective dose was found to be $0.1-42.48$ person Sv [11].

Individual dose records for one thousand five hundred and seventy-four (1574) OEWs from diagnostic radiology facilities were analyzed in this study during the 5 year period (2011-2015) and findings presented in Table 1 and Table 2. The percentage distribution is as follows: general radiographers (63\%), radiologists (13\%), CT technologists (17\%) and fluoroscopy technologists (7\%), who were all measurably exposed. The highest annual individual dose recorded was $8.48 \mathrm{mSv}$ received by an interventional radiologist in 2015 and the least being $1.27 \mathrm{mSv}$ for a CT technologist in 2012. During routine work, CT technologists are normally inside the control booth and are shielded from scatter radiation from the patient [12] [13]. The low annual individual dose demonstrates the adequacy of structural shielding in these facilities.

The monitored medical facilities increased by $31.25 \%$, while the exposed workers increased by $55.83 \%$ over the study period. This is attributed to the sharp rise in the number of diagnostic radiology facilities licensed or authorized by the Radiation Protection Board over the period. 
Table 1. Demonstrates an average annual effective dose.

\begin{tabular}{cccccc}
\hline \multirow{2}{*}{ Subgroup } & \multicolumn{5}{c}{ Average Annual Dose (mSv) } \\
\cline { 2 - 6 } & 2011 & 2012 & 2013 & 2014 & 2015 \\
\hline Radiographers & 1.09 & 1.11 & 1.03 & 0.94 & 1.70 \\
Radiologist & 1.12 & 1.04 & 1.12 & 0.88 & 1.36 \\
CT technologist & 0.94 & 0.96 & 1.04 & 1.00 & 1.45 \\
Fluoroscopy technologist & 0.95 & 1.15 & 0.36 & 0.68 & 0.91 \\
\hline
\end{tabular}

Table 2. Demonstrates an annual collective dose and percentage contribution of subgroups.

\begin{tabular}{cccccc}
\hline \multicolumn{5}{c}{ Collective Dose (person-Sv) } \\
\cline { 2 - 6 } & $\mathbf{2 0 1 1}$ & $\mathbf{2 0 1 2}$ & $\mathbf{2 0 1 3}$ & $\mathbf{2 0 1 4}$ & $\mathbf{2 0 1 5}$ \\
\hline Radiographers & $10.86(88.99 \%)$ & $19.11(88.61 \%)$ & $19.34(88.24 \%)$ & $17.55(91.17 \%)$ & $42.48(88.68 \%)$ \\
Radiologist & $0.65(5.3 \%)$ & $0.82(3.79 \%)$ & $0.87(3.99 \%)$ & $0.51(2.64 \%)$ & $1.40(2.91 \%)$ \\
CT technologist & $0.45(3.71 \%)$ & $1.38(6.41 \%)$ & $1.50(6.84 \%)$ & $1.09(5.68 \%)$ & $3.48(7.27 \%)$ \\
$\begin{array}{c}\text { Fluoroscopy } \\
\text { technologist }\end{array}$ & $0.24(2 \%)$ & $0.26(1.2 \%)$ & $0.21(0.94 \%)$ & $0.10(0.51 \%)$ & $0.54(1.14 \%)$ \\
$\begin{array}{c}\text { Total for } \\
\text { all subgroups }\end{array}$ & $12.2(100 \%)$ & $21.57(100 \%)$ & $21.92(100 \%)$ & $19.25(100 \%)$ & $47.9(100 \%)$ \\
\hline
\end{tabular}

For all the workers monitored, the doses observed over the 5-year period were well below the internationally recommended limit of $20 \mathrm{mSv}$ per year and this is due to the fact that the workers were sensitized on the essence of personal monitoring and radiation principle of optimization. This led to improvement in some of their radiation protection practices in the course of their work [14].

\section{Conclusions}

In this study, the annual dose records of diagnostic staff in different facilities (both urban and rural) for the period 2011-2015 were retrieved from the DMS and exported to excel 2010 for analysis. The period 2011-2015 was chosen because that was when a lot of occupationally exposed workers were monitored.

The average annual effective doses of occupational radiation exposure among diagnostic workers as demonstrated in Table 1 and Table 2 decreased substantially during the study period. This could be due to improvement in radiation protection protocols in the respective facilities. Exposed workers in the conventional $\mathrm{x}$-ray facilities received the highest individual doses. Correspondingly their collective dose represented $96 \%$ of the total collective dose during the period. Average doses per the medical institution and exposed workers were 5 and $0.73 \mathrm{mSv}$, respectively in the entire survey period. This study provided an opportunity to understand the trends in the occupational radiation doses and the working environment and will form the basis for a national database of exposures for radiation workers that can be used to assess potential adverse radiation 
effects.

\section{Recommendation}

This work serves as a baseline for personnel monitoring services in Ghana. It is therefore recommended that a further work should be carried out in other Laboratories both nationally and internationally in the subsequent years ahead.

\section{Conflicts of Interest}

The authors declare no conflicts of interest regarding the publication of this paper.

\section{References}

[1] Lee, W.J., et al. (2009) Occupational Radiation Doses among Diagnostic Radiation Workers in South Korea, 1996-2006. Radiation Protection Dosimetry, 136, 50-55.

[2] Model 6600 Automated TLD Reader with WinREMS ${ }^{\mathrm{TM}}$ (2002) Operator's Manual, Publication No. 6600-W-O-0602-005.

[3] Occupational Radiation Protection (2002) Radiation Protection and Safety Guide. GRPB-G3:2000.

[4] Ogundare, F.O. and Balogun, F.A. (2003) Whole Body Doses of Occupationally Exposed Female Workers in Nigeria. Journal of Radiological Protection, 23, 201-208.

[5] Bolus, N.E. (2008) Review of Common Occupational Hazards and Safety Concerns for Nuclear Medicine Technologist. Journal of Nuclear Medicine Technology, 36, 11-17. https://doi.org/10.2967/jnmt.107.043869

[6] Colgan, P.A., Currivan, L. and Fenton, D. (2008) An Assessment of Annual Whole-Body Occupational Radiation Exposure in Ireland (1996-2008). Radiation Protection Dosimetry, 128, 12-20. https://doi.org/10.1093/rpd/ncm235

[7] Glasgow, G.P., Eichling, J. and Yoder, R.C. (1906) Observations on Personnel Dosimetry for Radiotherapy Personnel Operating High-Energy LINACS. Health Physics, 50, 789-795. https://doi.org/10.1097/00004032-198606000-00010

[8] Gunduz, H., Zeyrek, C.T., Aksu, L. and Iask, S. (2004) Occupational Exposure to Ionizing Radiation in the Region of Anatolia, Turkey for the Period 1995-1999. Radiation Protection Dosimetry, 108, 293-301. https://doi.org/10.1093/rpd/nch025

[9] Hasford, F., Owusu-Banahene, J.K., Amoako, F., et al. (2011) Assessment of Annual Whole-Body Occupational Radiation Exposure in Medical Practice in Ghana. Radiation Protection Dosimetry, 149, 431-437. https://doi.org/10.1093/rpd/ncr318

[10] Huda, W. and Gordon, K. (1989) Nuclear Medicine Staff and Patient Doses in Manitoba. Health Physics, 56, 277-285.

https://doi.org/10.1097/00004032-198903000-00001

[11] International Commission on Radiological Protection (1990) Recommendations of the International Commission on Radiological Protection. ICRP Publication 60. Annals of the ICRP, 21, 1-3.

[12] International Atomic Energy Commission (IAEA) (1996) International Basic Safety Standards for Protection against Ionizing Radiation and for the Safety of Radiation Sources-Safety Series. 115.

[13] ICRU (1993) International Commission on Radiation Units and Measurements Quantities and Units in Radiation Protection Dosimetry. ICRU Report 51. 
[14] Korir, G.K., Wambani, J.S. and Korir, I.K. (2011) Estimation of Annual Occupational Effective Doses from External Ionizing Radiation at Medical Institutions in Kenya. South African Journal of Radiology, 15, a353.

https://doi.org/10.4102/sajr.v15i4.353 